\title{
Anaesthesia and Marfan's syndrome: case report
}

An 18-year-old male with Marfan's syndrome underwent surgery for repair of an ascending aortic dissection. The clinical features of this congenilal syndrome and the acute management of its complications are described. As elective surgery is frequently required for ocular, musculo-skeletal or cardiovascular problems in people with Marfan's syndrome, parients must be carefulty assessed preoperatively for specific complications.

Significant pulmonary problems include restriction of lung function due to pecius excavatum or kyphoscoliosis and intrinsic pulmonary involvement with emphysema, bronchogenic cysts and "honeycomb lung." This leads to a significant incidence of spontaneous pneumothorax and the danger of tension pneumothorax with positive pressure ventilation.

The commonest causes of sudden death are cardiovascular complications, in particular rupture and dissection of the ascending corta. Preoperative assessment should include echocardiography to determine the size of the aortic root. The anaesthetic technique chosen should both decrease myocardial contractility and avoid sudden increases in contractility, in order to minimise the risk of aortic dissection or rupture.

Key words

GENETIC FACTORS: Marfan's Syndrome; SYNDROME:

Marfan's Syndrome; complications: cardiovascular.

From the Department of Anaesthesia, St. Vincent's Hospital, Melbourne, Australia.

Address correspondence to: Dr. W. Podolakin, Department of Anaesthesia, St. Vincent's Hospital, Victoria Parade, Fitzroy, Victoria 3065. Australia.
The incidence of Marfan's syndrome in the general population is thought to be between 1:10,000 and 1:50,000.' Hence it is possible that at some stage during their practising life many anaesthetists will be called upon to treat such a patient. We recently anaesthetized a patient for a cardiac procedure who demonstrated most of the features of this generalised disorder of connective tissue.

\section{Case report}

An 18-year-old male presented to hospital four days after the acute onset of left sided chest and neck pain. The pain was associated with severe dyspnoea, nausea and faintness and lasted about 15 seconds. It was followed by constant, heavy retrosternal chest pain. Similar episodes of diffuse, heavy chest pain were described on several occasions over the previous two years.

The patient gave a history of multiple recurrent dislocations of both shoulders and also of a dislocation of his left ankle. He had undergone surgery at the age of 12 for the correction of a severe pectus excavatum deformity, at 15 years of age for osteo-chondritis dissecans of the left knee and at 17 years, for torsion of the right testis.

Examination of this tall $(185 \mathrm{~cm})$, thin $(62 \mathrm{~kg})$ patient revealed the typical features of Marfan's syndrome; an arm span that was greater than his height, a cathedral palate, winging of the scapulae, ulnar deviation of the metacarpophalangeal joints and residual pectus excavatum. He had also an abberant left radial artery, situated on the dorsum of the forearm.

There were significant abnormalities on examination of the cardiovascular system. The blood pressure in the left arm was $110 / 60 \mathrm{mmHg}$ and in the right arm $120 / 70 \mathrm{mmHg}$. His apex beat was widely displaced to the 7 th left intercostal space, mid axillary line. There was an ejection systolic murmur heard to the right of the sternum with a mid-systolic click at the left sternal edge.

A chest $x$-ray showed a prominent and slightly tortu ous aorta with cardiomegaly and a marked thoracic scoliosis. There were no interstitial pulmonary changes. His ECG showed right atrial hypertrophy and large left ventricular complexes. The following day an aortogram was performed, outlining a large false aortic sac with a possible entry site proximal to the innominate artery. The aortic root was not outlined. He was treated with oral 
atenolol, $50 \mathrm{mg}$ daily, with surgical intervention planned at a sub-acute stage. Despite this therapy there were further episodes of chest pain, with progressive weakening of his left axillary and brachial pulses, weakness of the left arm, and the development of an ejection systolic murmur over the left stemoclavicular joint. Surgery was eventually performed ten days after admission.

The patient was premedicated with morphine $10 \mathrm{mg}$ and scopolamine $0.4 \mathrm{mg}$ IM. On arrival in the operating room right radial and left dorsalis pedis arterial lines were placed, together with a triple lumen pulmonary artery catheter, inserted via the right internal jugular vein. All systemic and pulmonary artery pressures were within normal limits.

Anaesthesia was induced with diazepam $5 \mathrm{mg}$, fentanyl $30 \mu \mathrm{g} \cdot \mathrm{kg}^{-1}$, alcuronium $20 \mathrm{mg}$ and propranolol $1 \mathrm{mg}$. Additional maintenance was provided with 0.5 per cent halothane in oxygen. There were no cardiovascular responses to intubation or sternal splitting. Femoro-atrial bypass was established and the paticnt was cooled to $18^{\circ} \mathrm{C}$. The aortic cross-clamp was applied distal to the origin of the innominate artery, with cerebral perfusion from the femoral line via the left carotid artery and additional cerebral perfusion via direct cannulation of the right subclavian artery. An aneurysm of the ascending aorta which extended for an unknown distance beyond the innominate artery was found. Exposure was difficult because of the chest deformity. The aortic valve was normal. Surgery consisted of repair of the proximal aorta by a dacron graft from the level of the coronaries to the origin of the innominate. This covered most, but not all, of the intimal tear.

Post-bypass hypertension was easily managed with sodium nitroprusside and the patient was extubated 12 hours postoperatively. Cerebral function was normal.

Despite an uncventful postoperative course and subsequent discharge 12 days postoperatively the patient had further admissions for abdominal pain and haematuria and died suddenly at home two months later. As permission for a post mortem was refused, we can only assume these symptoms related to further aortic dissection.

\section{Discussion}

Marfan's syndrome is an inherited, autosomal dominant trait. About 15 per cent of cases are sporadic and apparently are the result of fresh mutations occurring in a getron cell of one or other parent; the other 85 per cent of patients have one parent affected. Paternal agc cffect is demonstrable in these sporadic cases; the average age of fathers of such patients is five to seven years higher than that of patients with inherited cases. ${ }^{2}$ The syndrome is characterised by a generalised defect of connective tissue, resulting from an unknown biochemical defect which produces a reduction in connective tissue elasticity and strength. The characteristic features and some potential anaesthetic problems can be recognised and anticipated on this basis. Pyeritz and McKusick ${ }^{3}$ base the diagnosis of the Marfan syndrome on the four criteria of characteristics, familial, ocular, cardiovascular and skeletal features. To make a diagnosis at least two of these criteria must be met.

As is anticipated, patients with Marfan's syndrome present with an increased incidence for ocular, cardiovascular or musculoskeletal surgery. Problems can occur within the first five years of life. Woolley et al. ${ }^{4}$ reviewed four children with the condition who underwent surgery. The earliest diagnosis was made at three months of age. The major threats to life, severe cardiovascular complications, may occur at any time from infancy to the seventh decade. These complications include dilatation, dissection, or rupture of the aorta and severe regurgitation of the aortic or mitral valve. These patients may also suffer coronary artery involvement, pulmonary artery dilatation, redundant cordac tendenae or an increased incidence of aortic coarctation. ${ }^{5,6}$ Published figures indicate the mean age of death as being 23-34 years. ${ }^{7.8}$

The most conspicuous external feature of the syndrome is increased length of the tubular bones. Body proportions are abnormal with long, narrow facies and arm span greater than height. The distance from sole to pubis is greater than from pubis to vertex. Excessive rib growth may produce pectus excavatum and, less commonly, pectus carinatum. Scoliosis is common and may occur at multiple sites along the thoracolumbar spine." There is usually muscular hypotonia which may predispose to inguinal, femoral or umbilical hemias. These frequently recur following surgical repair. As our patient demonstrates, recurrent dislocations because of joint laxity are a common feature which may require anaesthesia for surgical correction.

Consequent upon these musculoskeletal changes close attention must be paid to the proper positioning and careful handling of the anaesthetised patient to prevent injury and dislocations. Although Barr ${ }^{10}$ has referred to the potential for severe temporomandibular joint ostcoarthritis and dysfunction, difficult intubations attributable to this condition have not been reported. If intubation is necessary, however, excessive traction at laryngoscopy should be avoided to prevent temporomandibular joint dislocation.

Naturally, care in positioning applies to the awake patient prior to the administration of regional anaesthesia. Because of the increased size of these patients it is possible that the dose requirements for regional analgesia may be increased. Further, Miller and Katz ${ }^{11}$ suggest that the increased volume of the spinal canal in these patients may affect the required dose for spinal or epidural blockade.

The skeletal changes, in particular pectus excavatum 
and kyphoscoliosis, may result in decreased pulmonary function. However, even patients without a skeletal basis for pulmonary dysfunction demonstrate lower forced vital capacities than predicted, ${ }^{3}$ presumably as a result of earlier airway closure due to a lack of small airway elastic tissue support. This pulmonary dysfunction is further aggravated by the carly development of emphysema, bronchogenic cysts and honeycombed lungs. ${ }^{12}$ Spontaneous pneumothoraces are a frequent occurrence. ${ }^{13}$ The potential for the development of a pneumothorax must always be borne in mind during anaesthesia, particularly with positive pressure ventilation.

Weakness and redundancy of the supporting tissue of the lens is the cause of a characteristic finding in Marfan's syndrome - bilateral subluxation or dislocation of the lens. This occurs in up to 80 per cent of patients. Cataract development can be a complication of lens subluxation and a further indication for surgery. The axial length of the globe is increased, contributing to the tendency to myopia and an increased risk of retinal detachment.

Cardiovasculas complications are the most common immediate cause of death. Where a cause of death could be ascertained a cardiovascular problem was responsible in over 95 per cent of cases. ${ }^{\circ}$ Up to 60 per cent of persons believed to have Marfan's syndrome have auscultatory evidence of either mitral or aortic regurgitation or systolic clicks. ${ }^{14-15}$ However, sensitive diagnostic modalities such as echocardiography will reveal, irrespective of age, prolapse of at least the posterior mitral leaflet in over 80 per cent of patients. ${ }^{16.17}$ This syndrome of mitral valve prolapse (which has recently been reviewed ${ }^{18}$ ) is characterised by a mid-systolic click and is associated with an increased incidence of mitral regurgitation with myxoematous degeneration of the mitral valve ring. The presence of a click demands the appropriate antibiotic prophylaxis for bacterial endocarditis. However, because of the underlying collagen defect in Marfan's syndrome, antibiotic prophylaxis is necessary even in those patients without demonstrable valvular pathology.

Little attention has been paid to the changes in small coronary arteries. Over 20 years ago James ${ }^{19}$ described medial necrosis progressing to luminal narrowing in these vessels in Marfan's syndrome and other conditions such as muscular dystrophy. He noted that the small arteries supplying the sinus and $A V$ nodes were especially involved, probably explaining the higher frequency of arrhythmias and conduction disturbances.

Weakness in the region of the ascending aorta and other large arteries, where degenerate medial elastic fibres are replaced by collagenous metachromatically staining mucoid material, causes the most life-threatening abnormality in the Marfan syndrome. This cystic medial necrosis is the cause of progressive dilatation, dissection and/or rupture of the proximal portion of the ascending aorta. The predilection for involvement of the ascending aorta is not surprising as this area is subject to the greatest pulsatile expansion during systole. However, pulmonary and other large arteries may also be involved.

The type 2 aortic dissection as classified by De Bakey ${ }^{20}$ in which there is involvement of the ascending aorta ending proximal to the innominate artery, is the commonest type seen in Marfan's syndrome.

Although our patient showed no sign of aortic valve involvement, saccular expansion of the aortic root may lead to eventual aortic regurgitation with secondary ventricular hypertrophy, ventricular dilatation with mitral valve regurgitation, heart failure and angina. Thus resection of an aortic aneurysm may also dictate the need for associated valvular replacement or coronary artery bypass surgery.

It is important to realise that the catastrophic complications of aortic regurgitation, dissection and rupture nearly always occur after the ascending aorta dilates to greater than $6 \mathrm{~cm}$ in diameter in adults. ${ }^{3}$ As probably demonstrated by our patient this dilatation progresses gradually over many years. For this reason even those patients with Marfan's syndrome presenting for unrelated surgery must be approached as being of imminent risk of thoracic aortic rupture. In a review of the causes of death in 74 patients with Marfan's syndrome ${ }^{8}$ two deaths occurred in patients undergoing non-cardiac surgery. One was a documented casc of aortic rupture after surgery for funnel chest, the other, a cardiac death after orthopaedic surgery.

Early detection of aortic dilatation is difficult. Standard chest $x$-ray will often not reveal dilatation until aortic regurgitation or dissection has occurred as the part of the aorta to dilate first is usually within the cardiovascular silhouerte. Echocardiography greatly enhances the detection of cardiovascular abnormalities and improves both diagnosis and management. It has been suggested that all patients with the Marfan syndrome should undergo annual cardiac echocardiograms to detect dilatation with a view to elective repair. ${ }^{3}$ We believe all patients should be seriously considered for echocardiography prior to any surgery.

Because pulsatile How is more important than steadystate hypertension in producing or extending dissection, it would seem appropriate to introduce beta biocking agents, not only in those with djssection, but also prophylactically in those with documented dilatation to decrease myocardial contractility and the rate of aortic pressure rise. Unfortunately, there are as yet no randomised prospective trials of prophylactic beta blackade therapy reported in humans. However, in an animal model of turkeys prone to aortic dissection, decreasing the rate of aortic pressure rise with propranolol has prevented sud- 
den death. ${ }^{21}$ Inhalational agents, such as halothane, which reduce the velocity of left ventricular contraction, are ideal as either primary anaesthetics or as an adjuvant to a narcotic technique. Control of blood pressure alone by vasodilators, although attractive, may increase left ventricular ejection velocity and unless combined with beta blockade may not prevent dissection.

Whatever the anaesthetic technique, the primary consideration is the avoidance of sudden increases in myocardial contractility, producing an increase in aortic wall tension. Beat to beat monitoring by an intra-arterial cannula is helpful, but should be performed carefully in these patients who may be at increased risk from morbidity attributable to weakened arterial walls. These lines should be placed before induction in a patient who has been appropriately sedated.

In conclusion, while patients with Marfan's syndrome usually tolerate anaesthesia and surgery well, the presence of significant pre-existing cardiovascular disease and the potential for acute cardiovascular and respiratory complications necessitates that careful preoperative assessment is combined with skilful anaesthetic techniques in order to avoid potentially fatal complications.

\section{References}

1 Harrison's Principles of Internal Medicine. McGraw Hill Book Co., 1983, 10th Edition.

2 Murdoch JL, Walker BA, MCKusick WA. Panenterul age effects on the occustence of new mutations for the Marfan's syndrome. Ann Hum Genet 1972; 35: 331.

3 Pyeritz RE, MCKusick VA. The Marfan Syndrome. Diagnosis and management. N Engl J Med 1979; 300: 772.

4 Woolley MM, Morgan S, Hay D. Heritable disorders of connective tissue: Surgical and anaesthetic problems. J Paed Sur 1967; 2: 325.

5 The Heart. Ed. J. Willishurst. McGraw Hill Book Co. 1985; Gth Edition, p. 122

6 Eldridge $R$. Coarctation in the Marfan's Syndrome. Areh Int Mod 1964; $113: 342$.

7 Roberis WC, Honig HS. The spectrum of cardiovascular disease in the Marfan Syndrome: a clinico-morphologic study of 18 necropsy patients and comparison to 151 previously reported necropsy patients. Am Heart J 1982; 104 115.

8 Murdach $J L$, Walker BA, Halpern BL et al. Life expectancy and causes of death in the Marfan's Syndrome. N Engl J Med 1972; 286: 804.

9 Robins PR, Moe JH, Winter RB. Scoliosis in Marfan's Syndrome; its characteristics and results of treatment in 35 patients. J Bone Joint Surg (Am) 1975; 57: 358.

10 Barr A. Temperomandibular joint dysfunction and orofacial pain. Aust Dental J 1979; 24: 190.
11 Katz J, Benumof $J$, Kadis $L$. Anesthesia and uncommon diseases. WB Saunders Co., 2nd Edition, p. 68.

12 Bolande RP, Tucker AS. Pulmonary emphysema and other cardio-respiratory lesions as part of the Marfan abiotrophy. Paediatrics $1964 ; 33: 356$.

13 Turner JAM, Stanley $N N$. Fragile lung in the Marfan Syndrome. Thorax 1976; 31: 771.

14 McKusick VA. The cardiovascular aspects of Marfan's Syndrome: a heritable disorder of connective tissue. Circulation 1955; 11: 321.

15 Phormptutkul C, Rosenthal A, Nadas AS. Cardiac manifestations of Marfan Syndrome. Circulation 1973; $47: 587$.

16 Brown OR, De Mors H, Kloster FE. Aortic root dilatation and mitral valve prolapse in Marfan's Syndromc: an echocardiogram study. Circulation 1975; $51: 651$.

17 Spangler RD, Nora JJ, Lortscher RH. Echocardiography in Marfan Syndrome. Chest 1976; 69: 72.

18 Kowalski SE. Mitral valve prolapse. Can Anaesth Soc j 1985; 32 : 138.

19 James TN. An etiology concept concerning the obscure myocardopathies. Progr Cardiovase Disease 1964; 7:43.

20 De Bukey ME, Hewley WS, Cooley DA. Surgical managcment of the dissecting aneurysms of the aorta. $J$ Thor Cardiovasc Surg 1965; 49: 130.

21 Simpson CF, Kling JM, Palmer RF. Beta aminopropricnitrile-induced dissecting aneurysms of turkcys: treatment with propranolol. Toxicol Appl Pharmacol 1970; 16: 143.

\section{Résumé}

Un patient âgé de 18 ans atteint du syndrome de Marfan a subi une chirurgie de réparation pour une dissection de l'aorte ascendante. Les signes cliniques de ce syndrome congértital la conduite à faire en urgence et les complications sont décrits. Etant donné que la chirurgie élective est fréquemment requise pour les problèmes oculaires, musculo-squelettiques ou cardiovasculaires chez les patients atteints de ce syndrome, les patients doivent être évalués soigneusement en période préopératoire pour des complications spécifiques.

Les problèmes pulmonaires significatifs incluent la restric. sion de la fonction pulmonaire par un pectus excavanum ou une kyphoscoliose et une atteinte pulmonaire intrinseque avec de lemphysème, des kystes bronchogéniques et un "honeycamb lung". Ceci amènera une incidence significative de pneumothorax spontante et un danger de pneumothorax sous tension lors de la ventilation a pression positive.

Les causes les pius fréquentes de décès soudain sont les complications cardiovasculaires, en particuliè la rupture et la dissection de l'aorte ascendante. L'évaluation prêopératoire doit inclure l'échocardiographie afin de déterminer la grosseur de la racine aortique. La technique anesthésique choisie doit diminuer et éviter toute augmentation soudaine de la contractilité myocardique afin de minimiser le risque de dissection aortique ou de rupture. 